\title{
E-santé, littératie en santé, Web 2.0, floraison d'initiatives qui transforment la pratique
}

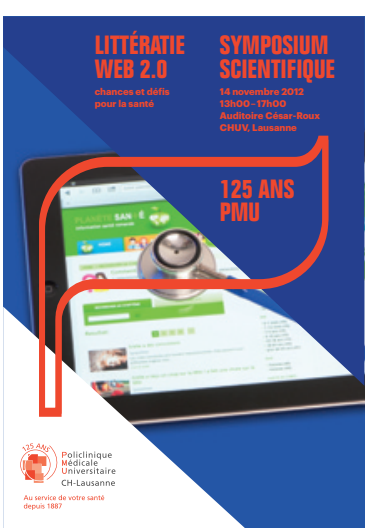

On parle aussi de M-health/ santé, à savoir de la médecine rendue «mobile» par les développements techniques et électroniques tels que ordinateurs, téléphones portables, satellites, moyens de monitorage des patients, télémédecine.

** Intéressant de noter cette nouvelle signification relationnelle de précautions universelles, terme utilisé d'abord pour des mesures très «matérielles» de protection en rapport par ex. avec les risques d'infection par les virus des hépatites ou du sida.

1 Martin J. Recherche médicale et échanges d'expériences par les patients eux-mêmes. Bull Méd Suisses. 2012;93(10):392.
Mindblowing... qui bouscule l'esprit comme un ouragan. A l'occasion de ses 125 ans, la Policlinique médicale universitaire de Lausanne (PMU) organisait le 14 novembre un symposium sous le titre «Littératie Web 2.0 - Chances et défis».

Pour un vieux comme moi, cela demande des traductions: $e$-santé fait référence à tout ce qui dans la sphère de l'information et de la communication est en rapport avec la santé et la médecine. ${ }^{*}$ La littératie en santé est la capacité de trouver de l'information et de comprendre et utiliser ces données de manière à prendre des décisions puis à suivre les instructions thérapeutiques (fondamentalement, il s'agit de lire, écrire, parler, écouter et calculer). Le concept de capacitation des patients (empowerment) en est proche. La recherche a bien démontré les liens entre le niveau de littératie des patients et les résultats thérapeutiques.

De nombreuses études montrent que, y compris dans les pays industrialisés, une proportion notable des malades sont illettrés en matière de santé, ne comprennent pas - ou mal - ce que disent les soignants. Rima Rudd, de Harvard, a eu une formule forte: dans une telle situation, continuer à prodiguer des soins comme si les patients comprenaient est simplement non éthique! Le Département états-unien de la santé a fait développer le «Health Literacy Universal Precautions Toolkit» pour aider les professionnels à être mieux compris des malades. **

L'expression Web 2.0 a été introduite vers l'an 2000 pour parler de sites qui vont au-delà d'un format statique pour permettre des interactions et collaborations; donnant lieu à un dialogue par les médias sociaux, avec création de contenus générés par les utilisateurs, au sein d'une communauté virtuelle. Autre expression du jargon, le crowdsourcing (littéralement, rechercher des compétences dans la foule): démarche où on tire profit de la créativité et du savoirfaire d'un grand nombre de personnes tout-venant, pour réaliser des tâches qui étaient jusqu'ici effectuées par des experts.

La PMU avait invité des spécialistes étrangers de haut vol: en plus de R. Rudd déjà citée, Denise Silber, très active dans ces développements en France notamment, et Beci Mesko, jeune médecin et entrepreneur hongrois (27 ans - impressionnant), manifestement une sorte de génie de la e-santé; il a créé plusieurs sites très actifs, enseigne «Médecine et Web 2.0» à Debrecen, termine un Ph.D. en génomique personnalisée et se décrit comme «medical futurist».
D. Silber a insisté sur le fait que l'intelligence collective (collectivement construite), ça existe et c'est important. Selon elle, Web 2.0 en santé est utile de quatre manières au moins: entre professionnels et patients, aux professionnels entre eux, aux patients entre eux (voir la recherche gérée par eux - [1]), et entre patients et leurs proches. P.-A. Michaud, vicedoyen à Lausanne, a rappelé que le site «ciao» destinés aux jeunes et traitant de thèmes les concernant (sexualité, drogue, etc.), lancé il y a vingt ans, reste apprécié.

Des réserves et craintes? Un médecin de famille a réagi en disant qu'était absent de la présentation de ces «merveilles» le corps du patient, le contact direct et physique entre soigné et soignant. Avec raison. A l'évidence, le rapport humain, le personal touch, n'est pas au premier plan - mais n'est pas exclu non plus. Une chose est certaine: il est exclu que le foisonnement d'activités électroniques en rapport avec santé et maladie, leur déterminants, les soins (y compris diagnostic et traitement), s'éteigne comme feu de paille. Il y a évidemment des risques à gérer: contrôle de qualité des sites; apprentissage du tri dans des masses de données, pour les professionnels comme pour les laïcs (le nettoyage y relatif des sites est dit $c u$ ration); confidentialité (mais aujourd'hui certains exposent volontairement leur dossier médical sur les réseaux sociaux... et cela leur a permis parfois d'être aidés; ainsi à propos de maladies rares).

Des enseignants universitaires présents ont souligné qu'il était essentiel que les médecins et autres professionnels abandonnent les réactions critiques qu'ils ont pu avoir quand un malade parle de ce qu'il/elle a trouvé sur Internet. Ceci doit faire partie intégrante de la formation: apprendre à ne pas voir là méfiance ou dilution de responsabilités mais utiliser ces sources au bénéfice du soignant comme à celui du soigné. Web 2.0 en médecine et santé doit être enseigné au même titre que d'autres compétences indispensables au médecin, en cherchant le bon dosage entre méthodes d'enseignement classique et e-learning. Au chapitre des néologismes, il a été fait référence aux «digital natives», à savoir la génération de ceux qui sont nés avec Internet et l'usage des réseaux sociaux: le médecin dialoguera de plus en plus avec des patients «non naïf» sur ce plan. Enfin, il y a là un champ de recherche en expansion rapide (cf. Journal of Medical Internet Research).

Jean Martin, ancien médecin cantonal et membre de la Rédaction 